\title{
Research Paper: Four-Year Prospective Evaluation of Femoral Neck Fractures: Types and Complications
}

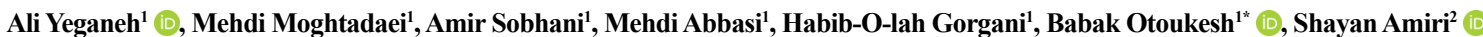

1. Department of Orthopedic Surgery, School of Medicine, Iran University of Medical Sciences, Tehran, Iran.

2. Department of Orthopaedic Surgery, Rasoul Akram Hospital, Iran University of Medical Sciences, Tehran, Iran.

\begin{tabular}{|c|c|}
\hline $\begin{array}{l}\text { Use your device to scan } \\
\text { and read the article online }\end{array}$ & \\
\hline 口iris & $\begin{array}{l}\text { ation of Femoral Neck Fractures: Types and Complications. Journal of Research in Orthopedic Science. 2020; 7(3):129-134. } \\
\text { http://dx.doi.org/10.32598/JROSJ.7.3.715.1 }\end{array}$ \\
\hline artis & doij: http://dx.doi.org/10.32598/JROSJ.7.3.715.1 \\
\hline
\end{tabular}

\section{(c) (i) (5)}

Article info:

Received: 01 May 2020

Revised: 23 May 2020

Accepted: 15 Jun 2020

Available Online: 01 Aug 2020
Keywords:

Osteonecrosis,

Femoral neck fracture,

Classification, Fractures,

Malunion

\begin{abstract}
A B S T RA C T
Background: Despite the advances in the methods of treating femoral neck fractures, treating some types of these fractures is still challenging. Therefore, understanding these fractures, their treatments, and the ways to control their complications are necessary for the orthopedists.

Objectives: In this study, we evaluate patients with acute femoral neck fractures with respect to the type of fractures and complications.

Methods: In a 4-year cross-sectional study, the patients with acute femoral neck fractures who were admitted to Rasoul Akram Hospital were selected. Anatomical features and the type of fracture were determined by using plain radiography and CT scan. Fractures were classified according to the Garden classification. The patients were also evaluated for any postoperative complications for at least 6 months.

Results: A total of 124 patients were enrolled. The Mean \pm SD age of the patients was $64.9 \pm 12.7$ years and $87(74.4 \%)$ were male. Based on the Garden classification, 7 fractures $(5.9 \%)$ belonged to type I, 10 fractures (8.5\%) to type II, 48 fractures (41\%) to type III, and 52 fractures (44.4\%) to type IV. Avascular necrosis in 28 cases (23.9\%), non-union in 14 cases $(12 \%)$, and claudication and pain in 35 cases $(29.9 \%)$ were noted. The mean age of patients was different between fracture groups $(\mathrm{P}=0.01)$.

Conclusion: Our results showed that most of the patients with femoral neck fractures admitted to Rasoul Akram Hospital were associated with displacement. In this study, the most common complications were pain and claudication, avascular necrosis of the femoral head, and nonunion. In sum, further displacement of the fracture will result in more complications.
\end{abstract}

\section{Introduction}

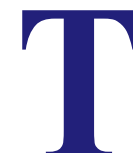

he prevalence of femoral neck fractures in youth is increasing due to serious car accidents. This type of fractures also happens in the elderly as a result of the improvements in medical care [1]. Despite the advances in the methods of treating these fractures, repairing unsolved fractures is still challenging and cannot be ignored [2].

* Corresponding Author:

Babak Otoukesh, $M D$.

Address: Department of Orthopedic Surgery, School of Medicine, Iran University of Medical Sciences, Tehran, Iran.

Phone: +98 (919) 8401007

E-mail: md.corresponding@gmail.com 
Therefore, understanding these fractures, their treatments, and ways to control their complications are necessary for the orthopedists. Choosing a treatment for femoral neck fractures is based on age, general health status, the presence of osteoarthritis, the patient's former activity level, and above all, the amount of fracture displacement [2].

Based on the available statistics, 1.7 million people experience femoral neck fractures annually and over 5 million people around the world suffer from disability following femoral fractures [3]. A femoral neck fracture is a problem that affects a person's entire life and some of its major complications include disability, dependency, and death. Also, femoral fractures cause major health issues problems. Especially for the elderly, 20\%-36\% of femoral neck fractures come along with death and complications one year after the damage [4]. Nonunion and avascular necrosis are the main complications of femoral neck fractures occurring in $17 \%-33 \%$ [5] and up to $25 \%$ of patients, respectively. Other complications occur in about $35 \%$ of the cases [6].

There is a standard method for classifying femoral neck fractures called the Garden classification. According to this classification, incomplete fractures are type I, complete fractures without displacement are type II, complete fractures with partial displacement are type III, and complete fractures with complete displacement type class IV [7].

This study aimed to evaluate femoral neck fractures in terms of anatomic features with respect to patients' radiologic images before and after the surgery in four years. Also, the incidence of postoperative complications is determined.

\section{Methods}

\section{Study Design and patients}

In a 4-year prospective study, all patients admitted to Rasoul Akram Hospital with acute femoral neck fractures were evaluated for anatomical features of the fracture and postoperative complications. Also, fractures were assessed based on the Garden classification by using anteroposterior and lateral views on plain radiography. Patients were excluded from the study if their radiological examination was incomplete. The data on every patient were collected in a checklist prepared by the researcher. All patients underwent CT scans for measuring the femoral neck version angle and the mid-coronal line was the criterion for the measurements on the axial view ( 0 to 30 degrees were assumed normal). The patients were fol- lowed for complications every 6 months up to 4 years and the overall incidence of each complication was checked.

\section{Statistical Analysis}

The data collected from the patients were analyzed in SPSS version 18 . We used mean and standard deviation for continuous variables and frequency for categorical ones. Also, all comparisons were done based on the Garden classifications and femoral neck version angle. The Chi-square test was used to examine the significance of the relationship between gender and the incidence of various complications with the Garden classification. Oneway ANOVA analysis was used to compare the mean age between the various types of Garden classification. $\mathrm{P}<0.05$ was considered statistically significant in all tests.

\section{Ethical issues}

The patients gave their informed written consent before the study. The study was approved by the Ethics Committee of Iran University of Medical Sciences and the researchers adhered to the codes of the Declaration of Helsinki and its later amendments during the study period.

\section{Results}

The current study was carried out on 124 patients at Rasoul Akram Hospital to examine their femoral neck fractures for anatomical features and complications. Seven patients were excluded from the study because of missing follow-up visits. The Mean $\pm \mathrm{SD}$ age of the subjects was $64.9 \pm 12.7$ years (range: $17-91$ years). The majority of patients were in the 60-69 age group which included 41 patients and the number of patients below 40 was only $5(4.3 \%)$. Also, the majority of patients were male (87 people, $74.4 \%$ ).

Fifty-one patients $(43.6 \%)$ had the left femoral neck fractures and 66 patients (56.4\%) suffered from right femoral neck fractures. Based on the Garden classification, 7 patients $(5.48 \%)$ were in type I, 10 patients $(8.55 \%)$ in type II, 48 patients (41.03\%) in type III, and 52 patients $(44.44 \%)$ in type IV (Figure 1). In femoral neck version assessment, 30 cases had anteversion with more than 30 degrees and 17 cases had retroversion from -1 to 30 and the total average version was 17. Complications included avascular necrosis in 28 patients $(23.4 \%)$, nonunion in 14 patients $(12 \%)$, pain and claudication $(24.4 \%)$ and postfixation infection in 4 patients (3.4\%) (Figure 2).

The statistical evaluation showed no significant relationship between the Garden classification and variables 
Table 1. Comparison of demographic data and complications of femoral neck fractures based on the Garden classification

\begin{tabular}{|c|c|c|c|c|c|}
\hline \multirow[b]{2}{*}{ Variable } & \multicolumn{4}{|c|}{ Garden Classification } & \multirow[b]{2}{*}{$\mathbf{P}$} \\
\hline & $\begin{array}{l}\text { Type I } \\
(n=7)\end{array}$ & $\begin{array}{l}\text { Type II } \\
(n=10)\end{array}$ & $\begin{array}{l}\text { Type III } \\
(n=48)\end{array}$ & $\begin{array}{l}\text { Type IV } \\
(n=52)\end{array}$ & \\
\hline Age $(y)$, Mean $\pm S D$ & $52.1 \pm 10.6$ & $61.1 \pm 16.0$ & $64.6 \pm 13.6$ & $67.6 \pm 10.3$ & 0.014 \\
\hline Gender (male), No. (\%) & $5(71.4)$ & $7(70)$ & 35 (72.9) & $40(76.9)$ & 0.948 \\
\hline Avascular necrosis, No. (\%) & - & $1(10)$ & $10(20.8)$ & $17(32.7)$ & 0.126 \\
\hline Nonunion, No. (\%) & $1(14.3)$ & $1(10)$ & - & - & 0.142 \\
\hline
\end{tabular}

of gender $(\mathrm{P}=0.948)$, the prevalence of avascular necrosis $(\mathrm{P}=0.126)$, nonunion $(\mathrm{P}=0.142)$, and pain and claudication $(\mathrm{P}=0.072)$. The only positive and significant relationship was between age and the Garden classification in a way that the patients in type IV had a significantly higher mean age compared to type $1(\mathrm{P}=0.014)$. Also, 4 cases of infection were observed in types III and IV.

The comparison of demographic data and complications of femoral neck fractures based on the Garden classification are presented in Table 1.

\section{Discussion}

Femoral neck fractures usually occur with two different mechanisms. In the first one, the fracture follows a high energy trauma (like car accidents, falling from a height, etc.) and the other one (and the most common type) occurs in people with osteoporosis following a low energy trauma [2]. About $20 \%$ to $36 \%$ of femoral neck fractures, especially in older patients, may lead to death and complications about after one year [8-11]. About 1.7 million hip bone fractures happen every year and this number will rise to 2.6 million until 2025 and 6.3 million until 2050 [12].
One-third of these fractures occur in Asia and mainly in China [13]. Femoral neck fractures are common among these fractures and include $53 \%$ of all proximal femurs and $3.6 \%$ of all fractures [14]. Femoral neck fractures are called unsolved fractures because they occur with a high rate of femoral head necrosis and nonunion after osteosynthesis. Currently, there is no standard guideline for treating this type of fractures that end in minimum complications [15].

The treatment of fractures depends on the age and the pattern of fractures. Fractures with displacement are usually treated with surgery, especially joint replacement. In older patients with displaced fractures, many surgeons recommend replacement, but closed or open reduction and fixation with screws or plates are preferred in the younger people. However, the necessity of surgery for treating femoral neck fractures without displacement is still under debate $[16,17]$. Conservative treatment for the cases without displacement and impacted intracapsular fractures is well-explained [18, 19]. Some researchers recommend internal fixation with a screw [20].

\section{Classification}

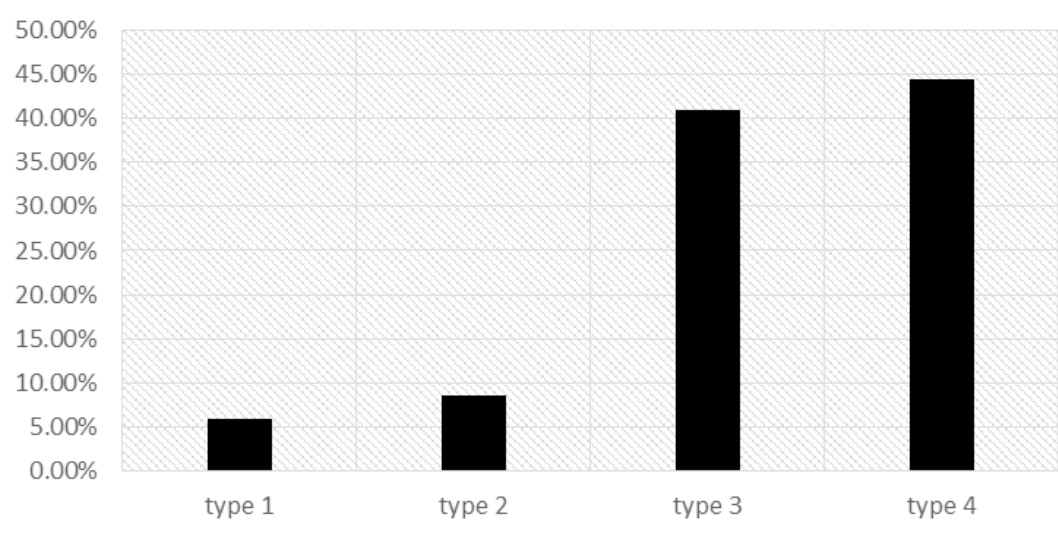

Figure 1. Frequency of fractures based on Garden classification 


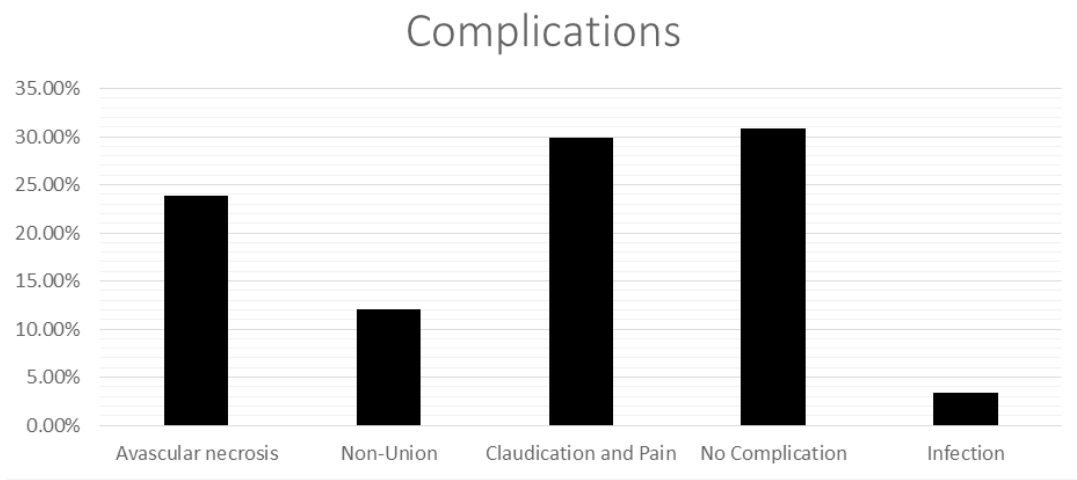

Figure 2. Frequency of patients' complications

Orthopedic Science

In 1961, Garden proposed a classification system for femoral neck fractures which is useful for impacted fractures without displacement and incomplete fractures [2123]. Although the Garden classification is well-accepted, its usefulness is still under discussion. For example, distinguishing fractures without displacement from a fracture with displacement is usually difficult with plain radiography $[24,25]$. In a study by Zelvodki et al., only $34 \%$ of surgeons from 5 states in the U.S. and Canada were able to distinguish between all types of the Garden classification in patients with femoral neck fractures. In this study, all surgeons were provided by the data of 298 patients with femoral neck fractures. Nevertheless, $46 \%$ of surgeons could distinguish between all types with and without displacement (i.e., distinguishing between types I/II from the Garden classification and types III/IV) [26].

The posterior angle of the femoral head in impacted fractures has a great impact on the need for reoperation and avascular necrosis after the internal fixation [16, 25]. However, no efficient method is available for measuring the displacement of the femoral head [27]. In the current study, the rates of postoperative complications, avascular necrosis, nonunion and pain, and claudication in patients without displacement (i.e., type I/II) were 5.8\%, 11.7\%, and 17.6\%, respectively, while in other studies, these rates were reported as $10 \%-20 \%, 10 \%$, and $20 \%-30 \%$ [27-29]. The results of the current study on pain and claudication and avascular necrosis are a little lower than other studies. The different treatment methods and patients' ages could describe the discrepancy between the results of our study and others'.

In the current study and based on the Garden classification, 7 cases $(8.9 \%)$ had type I, 10 cases $(8.5 \%)$ type II, 48 cases (41\%) type III, and 52 cases (44.4\%) type IV. In a study by Dou et al. in 2013, these rates were 5\%, $8 \%$, $41 \%$, and $46.1 \%$, which are close to those of our study except that the sample size of the population under study was 466 patients in their study and 117 in ours [30]. A recent study about the treatment results of the surgery and fixation of bones with screws in adults' femoral neck fractures by Dasht Bozorg et al. (2011) in Iran showed that based on the Garden classification, 2 patients had fracture type I, 3 patients had fracture type II, 18 patients had fracture type III, and 14 patients had fracture type IV. Thirty-two patients were treated using the open method (76.2\%) and 10 patients (23.8\%) with the closed method. Twelve patients $(28.6 \%)$ had nonunion and 7 patients (16.7\%) suffered from femoral head necrosis and 4 of these cases came with a union.

All cases of nonunion occurred in patients who were treated by open fixation [31]. Moghtadaei et al. (2008) studied 80 patients, who were treated using internal fixation, and a total of 29 patients $(36.3 \%)$ had experienced at least one of the complications. The complications were as follows: 19 patients $(23.8 \%)$, avascular necrosis; 12 patients (15\%), the nonunion; 3 patients $(3.75 \%)$ infection; and 28 patients (35\%), pain and claudication. The complications were lower in femoral base fractures and higher in femoral subcapital and trans-cervical fractures $(\mathrm{P}=0.016)$. Also, the rate of complications in patients with displaced fractures was more than that in the patients with non-displaced fractures $(\mathrm{P}=0.001)$ [32].

In the current study, the rate of complications was more in types III and IV of the Garden classification. However, this difference was not statistically significant which may be due to the misdiagnosis caused by a mismatch between plain radiographs and CT scans.

Chen et al. in a study on femoral neck fractures found that a CT scan was more reliable than plain radiographs for the classification of femoral neck fractures [33]. Mikaeil Hajializade et al. in an experimental study found that locally using simvastatin and ezetimibe-loaded nanofibers would augment bone healing and prevent later nonunion complications [34]. 
A previous study in China by Dou et al. had also reached the same results. They had concluded in their study that some cases of fractures are type I according to the plain radiography but were reported as type IV according to the CT scan results [30]. In a study on femoral neck fractures by Karim Pisoudeh et al in 2019, they showed that reducing the delay for surgery, increasing anatomic reduction, and preventing the shortcomings of the femoral neck can improve the quality of life, reduce complications, and decrease the economic burden [35]. In a study on 2015 Abolghasemian et al found that smoking have statistically significant association with the time to femoral head collapse in patients who suffer from femoral head osteonecrosis due to trauma or any other causes [36].

\section{Conclusion}

Our results showed that most of the femoral neck fractures admitted to Rasoul Akram Hospital were associated with displacement. In this study, the most common complications were pain and claudication, avascular necrosis of the femoral head, and nonunion. In sum, more displacement of the fracture will lead to more complications. We suggest that further studies be done for evaluating the causes of the complications, the way to prevent them, and the relations between the type of surgery and the complications.

\section{Ethical Considerations}

\section{Compliance with ethical guidelines}

This study ethically approved by the Ethics Committee of Iran University of Medical Sciences. also it observed the Helsinki Declaration and its later amendments and before the study, the patients gave their informed consent to participate in this study.

\section{Funding}

This research did not receive any grant from funding agencies in the public, commercial, or non-profit sectors.

\section{Authors' contributions}

All authors contributed in preparing this article.

\section{Conflict of interest}

The authors declared no conflict of interest.

\section{References}

[1] Tornetta P, Court-Brown C, Heckman J, McQueen M, Ricci W, Flynn J, et al. Rockwood, green, and wilkins fractures in adults and children. 8th edition. Texas: Lippincott-Raven comp; 2014.

[2] Canale S, Jones L, Daugherty K. Campbell's operative orthopaedics. 9th edition. Philadelphia: Mosby Comp; 1998.

[3] Kristensen TB, Vinje T, Havelin LI, Engesæter LB, Gjertsen JE. Posterior approach compared to direct lateral approach resulted in better patient-reported outcome after hemiarthroplasty for femoral neck fracture. Acta Orthop. 2017; 88(1):29 34. [DOI:10.1080/17453674.2016.1250480] [PMID] [PMCID]

[4] Macke C, Krettek C. Femoral neck fractures in the elderly. In: Egol KA, Leucht $P$, editors. Proximal Femur Fractures. New York City: Springer; 2018. [DOI:10.1007/978-3-319-64904-7_6]

[5] Asnis SE, Wanek-Sgaglione L. Intracapsular fractures of the femoral neck. Results of cannulated screw fixation. JBJS. 1994; 76(12):1793-803. [DOI:10.2106/00004623199412000-00005] [PMID]

[6] Lu-Yao GL, Keller RB, Littenberg B, Wennberg JE. Outcomes after displaced fractures of the femoral neck. A metaanalysis of one hundred and six published reports. Orthop Trauma Dir. 2005; 3(3):29-33. [DOI:10.1055/s-2005-919113]

[7] RK L. Fractures of the Neck of the femur. In: Bucholz R Heckman J, Court-Brown C, editors. Rockwood and Green's Fractures in Adults. 6th edition. Philadelphia: Lippincott, Williams \& Wilkins; 2006.

[8] Baumgaertner MR, Curtin SL, Lindskog DM, Keggi JM. The value of the tip-apex distance in predicting failure of fixation of peritrochanteric fractures of the hip. J Bone Joint Surg. 1995; 77(7):1058-64. [DOI:10.2106/00004623-199507000-00012] [PMID]

[9] Goodman SB, Bauer TW, Carter D, Casteleyn PP, Goldstein $\mathrm{SA}$, Kyle RF, et al. Norian SRS cement augmentation in hip fracture treatment. Laboratory and initial clinical results. Clin Orthop Relat Res. 1998; 348:42-50. [DOI:10.1097/00003086199803000-00009]

[10] Gundle R, Gargan M, Simpson A. How to minimize failures of fixation of unstable intertrochanteric fractures. Injury. 1995; 26(9):611-4. [DOI:10.1016/0020-1383(95)00125-S]

[11] Mattsson P, Alberts A, Dahlberg G, Sohlman M, Hyldahl HC, Larsson S. Resorbable cement for the augmentation of internally-fixed unstable trochanteric fractures: A prospective, randomised multicentre study. Bone Joint J. 2005, 87(9):1203-9. [DOI:10.1302/0301-620X.87B9.15792] [PMID]

[12] Peeters CM, Visser E, Van de Ree CL, Gosens T, Den Oudsten BL, De Vries J. Quality of life after hip fracture in the elderly: A systematic literature review. Injury. 2016; 47(7):1369-82. [DOI:10.1016/j.injury.2016.04.018] [PMID]

[13] Ling X, Aimin L, Xihe Z, Xiaoshu C, Cummings SR. Very low rates of hip fracture in Beijing, People's Republic of China: The beijing osteoporosis project. Am J Epidemiol. 1996; 144(9):9017. [DOI:10.1093/oxfordjournals.aje.a009024] [PMID]

[14] Thorngren KG, Hommel A, Norrman PO, Thorngren $\mathrm{J}$, Wingstrand $\mathrm{H}$. Epidemiology of femoral neck fractures. Injury. 2002; 33(Suppl. 3):1-7. [DOI:10.1016/S00201383(02)00324-8] 
[15] Karaeminogullari O, Demirors H, Atabek M, Tuncay C, Tandogan R, Ozalay M. Avascular necrosis and nonunion after osteosynthesis of femoral neck fractures: Effect of fracture displacement and time to surgery. Adv Ther. 2004; 21(5):335-42. [DOI:10.1007/BF02850038] [PMID]

[16] Conn KS, Parker MJ. Undisplaced intracapsular hip fractures: Results of internal fixation in 375 patients. Clin Orthop Relat Res. 2004; 421:249-54. [DOI:10.1097/01. blo.0000119459.00792.c1]

[17] Cserhati P, Kazár G, Manninger J, Fekete K, Frenyo S. Nonoperative or operative treatment for undisplaced femoral neck fractures: A comparative study of 122 non-operative and 125 operatively treated cases. Injury. 1996; 27(8):583-8. [DOI:10.1016/S0020-1383(96)00073-3]

[18] Jain R, Basinski A, Kreder HJ. Nonoperative treatment of hip fractures. Int Orthop. 2003; 27(1):11-7. [DOI:10.1007/ s00264-002-0404-y] [PMID] [PMCID]

[19] Raaymakers E, Marti R. Non-operative treatment of impacted femoral neck fractures. A prospective study of 170 cases. Bone Joint J. 1991; 73(6):950-4. [DOI:10.1302/0301620X.73B6.1955443]

[20] Bjørgul K, Reikerås O. Outcome of undisplaced and moderately displaced femoral neck fractures: A prospective study of 466 patients treated by internal fixation. Acta Orthop. 2007; 78(4):498-504. [DOI:10.1080/17453670710014149] [PMID]

[21] Blundell CM, Parker MJ, Pryor GA, Hopkinson-Woolley J, Bhonsle SS. Assessment of the AO classification of intracapsular fractures of the proximal femur. Br J Bone Joint Surg. 1998; 80(4):679-83. [DOI:10.1302/0301-620X.80B4.0800679]

[22] Garden RS. Low-angle fixation in fractures of the femoral neck. Bone Joint J. 1961; 43(4):647-63. [DOI:10.1302/0301620X.43B4.647]

[23] Crnković T, Gašpar D, Đurović D, Podsednik D, Slišurić F. New insights about suprapatellar cyst. Orthop Rev (Pavia). 2012; 4(1):e9. [DOI:10.4081/or.2012.e9] [PMID] [PMCID]

[24] Thomsen N, Overgaard S, Olsen L, Hansen H, Nielsen S. Observer variation in the radiographic classification of ankle fractures. Bone Joint J. 1991; 73(4):676-8. [DOI:10.1302/0301620X.73B4.2071659]

[25] Zlowodzki M, Bhandari M, Keel M, Hanson BP, Schemitsch E. Perception of Garden's classification for femoral neck fractures: an international survey of 298 orthopaedic trauma surgeons. Arch Orthop Trauma Surg. 2005; 125(7):503-5. [DOI:10.1007/s00402-005-0022-4] [PMID]

[26] Palm H, Gosvig K, Krasheninnikoff M, JacobsenS, GebuhrP. A new measurement for posterior tilt predicts reoperation in undisplaced femoral neck fractures: 113 consecutive patients treated by internal fixation and followed for 1 year. Acta Orthop. 2009; 80(3):303-7. [DOI:10.3109/17453670902967281] [PMID] [PMCID]

[27] Rogmark C, Flensburg L, Fredin H. Undisplaced femoral neck fractures-no problems? A consecutive study of 224 patients treated with internal fixation. Injury. 2009; 40(3):274-6. [DOI:10.1016/j.injury.2008.05.023] [PMID]

[28] Parker MJ, White A, Boyle A. Fixation versus hemiarthroplasty for undisplaced intracapsular hip fractures. Injury. 2008; 39(7):791-5. [DOI:10.1016/j.injury.2008.01.011] [PMID]
[29] Gjertsen JE, Fevang JM, Matre K, Vinje T, Engesæter LB. Clinical outcome after undisplaced femoral neck fractures: A prospective comparison of 14,757 undisplaced and displaced fractures reported to the Norwegian Hip Fracture Register. Acta Orthop. 2011; 82(3):268-74. [DOI:10.3109/17 453674.2011.588857] [PMID] [PMCID]

[30] Ling Du C, long Ma X, Zhang T, feng Zhang H, guang Wang $\mathrm{C}$, Zhao F, et al. Reunderstanding of garden type I femoral neck fractures by 3-dimensional reconstruction. Orthop. 2013; 36(6):820-5. [DOI:10.3928/01477447-20130523-31] [PMID]

[31] Dashtbozorg A, Mehdinassab SA, Badakhshanmehr F. Outcome assessment of surgical treatment of femoral neck fracture in adults by screw fixation (short term results). Iran J Orthop Surg. 2011; 9(2):49-54. http://ijos.ir/article-1-30-en.html

[32] Moghtadaei M, Malekpoor S, Shahim S, Shamsoddini A, Zangi M, Akbariyan E. [Evaluation of complication after treatment of femoral neck fracture by method of internal fixation (Persian)]. J Artesh Univ Med Sci. 2009; 6(4):225-31.

[33] Chen W, Li Z, Su Y, Hou Z, Zhang Q, Zhang Y. Garden type I fractures myth or reality? A prospective study comparing CT scans with X-ray findings in Garden type I femoral neck fractures. Bone. 2012; 51(5):929-32. [DOI:10.1016/j. bone.2012.07.027] [PMID]

[34] Hajializade M, Moghtadaei M, Mirzaei A, Abdollahi Kordkandi Sh, Babaheidariane P, Pazoki-Toroudi H, et al. Significant effect of simvastatin and/or ezetimibe-loaded nanofibers on the healing of femoral defect: An experimental study. Mater Sci Eng C Mater Biol Appl. 2020; 111:110861 [DOI:10.1016/j.msec.2020.110861] [PMID]

[35] Pisoudeh K, Gharanizadeh K, Sarshar MR, Mahmoudi M. Surgical treatment outcome in young adults with femoral neck fractures. J Res Orthop Sci. 2020; 7(1):23-8. [DOI:10.32598/JROS.7.1.23]

[36] Abolghasemian M, Ramezan Shirazi M, Gharanizadeh K, Yeganeh A, Safir O, Gross AE, et al. Factors associated with the course of femoral head osteonecrosis: A retrospective study. J Res Orthop Sci. 2015; 2(2):e1779. [DOI:10.17795/soj-1779] 